\title{
Cognitive mechanisms and motor control during a saccadic eye movement task: evidence from quantitative electroencephalography
}

Mecanismos cognitivos e controle motor durante uma tarefa de movimento sacádico dos olhos: evidências de eletroencefalografia quantitativa

Claudia Diniz',2,11, Bruna Velasques, 1,2,10,11, Juliana Bittencourt, ${ }^{1,2,11}$, Caroline Peressutti1 , Sergio Machado7, Silmar Teixeira', Joana Luz Santos,1,11, José Inácio Salles 10,14, Luis F. Basile ${ }^{3,4}$, Renato Anghinah ${ }^{15}$, Elie Cheniaux ${ }^{12,13}$, Antonio Egidio Nardi ${ }^{7,}$, Mauricio Cagy ${ }^{5}$, Roberto Piedade', Oscar Arias-Carrión ${ }^{9}$, Pedro Ribeiro 1,2,6

\begin{abstract}
The saccadic movement is an important behavioral measure used to investigate several cognitive processes, including attention and sensorimotor integration. The present study aimed at investigating changes in beta coherence over frontal, motor, occipital, and parietal cortices during the performance of two different conditions of a prosacadic paradigm. The conditions involved a different pattern of stimulus presentation: a fixed and random stimulus presentation. Twelve healthy volunteers (three male, mean age of 26.25 (SD=4.13) performed the task, while their brain activity pattern was recorded using quantitative electroencephalography. The results showed an interaction between factors condition and moment for the pair of electrode C3/C4. We observed a main effect for moment to CZ/C4, FZ/F3, and P3/PZ. We also found a main effect for condition to FZ/F4, P3/P4, and 01/02. Our results demonstrated an important role of the inter-connection of the two hemispheres in visual search and movement preparation. The study demonstrates an automation of action and reduction of the focus of attention during the task. We also found that the inter-hemispheric beta coherence plays an important role in the differentiation of the two conditions, and that beta in the right frontal cortex is able to differentiate the conditions, demonstrating a greater involvement of procedural memory in fixed condition. Our results suggest a neuronal specialization in the execution of prosacadic paradigm involving motor task sequence.
\end{abstract}

Key words: beta coherence, motor control, qEEG, saccadic eye movement, sensorimotor integration, visuospatial attention.

\section{RESUMO}

O movimento sacádico é uma importante medida de comportamento usada para investigar vários processos cognitivos, incluindo atenção e integração sensório-motora. O presente estudo teve como objetivo investigar as mudanças na coerência em beta nos córtices frontal, motor, parietal e occipital durante a realização de duas condições diferentes de um paradigma do movimento sacádico. As condições envolveram um padrão diferente de apresentação do estímulo: a apresentação do estímulo fixo e do aleatório. Doze voluntários saudáveis (três do sexo masculino, com idade média de 26,25; DP=4,13) realizaram a tarefa, enquanto o seu padrão de atividade cerebral era monitorado, usando eletroencefalografia quantitativa. Os resultados mostraram uma interação entre condição dos fatores e momento para o par de eletrodos C3/C4. Observou-se um efeito principal ao momento para CZ/C4, FZ/F3 e P3/PZ. Encontrou-se também um efeito principal à condição para FZ/F4, P3/P4 e 01/O2. Os resultados demonstram um importante papel da ligação interconexão entre os dois hemisférios, em busca visual e preparação do movimento. 0 estudo demonstra uma automatização da ação e uma redução do foco de atenção durante a ta-

\footnotetext{
'Brain Mapping and Sensory Motor Integration, Institute of Psychiatry of the Federal University of Rio de Janeiro (IPUB/UFRJ), Rio de Janeiro RJ, Brazil; Institute of Applied Neuroscience (IAN), Rio de Janeiro RJ, Brazil;

${ }^{3}$ Division of Neurosurgery, University of São Paulo Medical School, São Paulo SP, Brazil;

«Laboratory of Psychophysiology, Department of Psychology and Phonoaudiology, Universidade Metodista de São Paulo (UMESP), São Bernardo do Campo SP, Brazil; ${ }^{5}$ Division of Epidemiology and Biostatistics, Institute of Health Community, Federal Fluminense University (UFF), Rio de Janeiro RJ, Brazil;

${ }^{6}$ School of Physical Education, Bioscience Department, Rio de Janeiro Federal University (UFRJ), Rio de Janeiro RJ, Brazil;

${ }^{7}$ Panic \& Respiration Laboratory, Institute of Psychiatry, Federal University of Rio de Janeiro (UFRJ), Rio de Janeiro RJ, Brazil;

${ }^{8}$ National Institute of Translational Medicine (INCT-TM), Rio de Janeiro RJ, Brazil;

${ }^{9}$ Department of Neurology, Phillips University Marburg, Marburg, Germany;

${ }^{10}$ Neuromuscular Research Laboratory, National Institute of Traumatology and Orthopaedics (NITO), Rio de Janeiro RJ, Brazil;

${ }^{11}$ Neurophysiology and Neuropsychology of Attention, Institute of Psychiatry of the Federal University of Rio de Janeiro (IPUB/UFRJ), Rio de Janeiro RJ, Brazil;

${ }^{12}$ Anxiety \& Depression Laboratory, Institute of Psychiatry of Federal University of Rio de Janeiro (IPUB/UFRJ), Rio de Janeiro RJ, Brazil;

${ }^{13}$ Department of Medical Specialties, State University of Rio de Janeiro (UERJ), Rio de Janeiro RJ, Brazil;

${ }^{14}$ Brazilian Volleyball Confederation;

${ }^{15}$ Departments of Neurology, School of Medicine, University of São Paulo, São Paulo SP, Brazil.

Correspondence: Bruna Velasques; Rua São Francisco de Assis 300 / apto. 103; 22790-530 Rio de Janeiro RJ - Brasil; E-mail: bruna_velasques@yahoo.com.br Conflict of interest: There is no conflict of interest to declare.

Received 12 December 2011; Received in final form 20 February 2012; Accepted 27 February 2012
} 
refa. Identificou-se também que a coerência em beta entre regiões inter-hemisféricas desempenha um papel importante na diferenciação entre as duas condições. Ainda, beta no córtex frontal direito é capaz de diferenciar as condições, demonstrando-se um maior envolvimento da memória de procedimento em condição fixa. Sendo assim, os presentes resultados sugerem especialização neuronal na execução do paradigma prossacádico envolvendo sequência de tarefa motora.

Palavras-Chave: coerência beta, controle motor, EEGq, movimentos oculares sacádicos, integração sensório-motora, atenção visuoespaciais.

Oculomotor paradigms have been used to characterize sensorimotor and cognitive deficits related to the different neurological and psychiatric disorders ${ }^{1}$. Specifically, the saccadic eye movement (SEM) is widely used to investigate sensorimotor integration and information processing in several cortical areas ${ }^{2}$. The search for the target stimulus involves programming and orientation of the SEM, which demonstrates the cognitive processes participation, including attention. The SEM corresponds to the first stages of information processing, i.e., to the stimulus identification. Hence, a strong correlation has been shown in the activation of cortical areas involved in programming the saccadic movement and attention regulation ${ }^{3}$.

Coherence is an electroencephalography (EEG) measure of binding, expressing the coupling between cortical areas ${ }^{4}$. A coherence increase represents the co-activation of two brain areas for a certain task ${ }^{5}$. Among the frequency bands related to premotor and motor activities, the beta band (from 12 to $30 \mathrm{~Hz}$ ) is largely investigated, and some studies have demonstrated a beta decrease during the preparation and execution of voluntary movements. Furthermore, it is a fast frequency of reduced amplitude that indicates mental and attention activities $^{6}$. The activation of cortical areas involved in sensorimotor integration, attention and visual processing shows the connection between these processes ${ }^{7}$.

We have chosen to investigate beta coherence over the frontal, central, parietal, and occipital cortices, once these areas are directly related to the preparation and control of eye movement. The pairs of electrodes investigated included F3/ F4, FZ/F3, FZ/F4, C3/C4, CZ/C3, CZ/C4, P3/P4, P3/PZ, P4/ $\mathrm{PZ}, \mathrm{O} 1 / \mathrm{O} 2, \mathrm{O} 1 / \mathrm{OZ}$ and $\mathrm{OZ} / \mathrm{O} 2$. Although the neuroanatomy of SEM is well-known ${ }^{8}$, little is known about the electrophysiology of these areas. Little is known about how these areas communicate with each other.

In this context, this study sought to investigate the electrophysiological changes produced by the execution of two saccadic tasks: fixed and random. Specifically, we investigated the electrophysiological changes (i.e., beta coherence) over the frontal, central, parietal, and occipital cortices during the motor execution of saccades. The investigated areas take part in the perception and execution of a motor act and the planning of saccade movements 9 . We expect to find different patterns of beta coherence between conditions, i.e. fixed and random conditions. Once beta oscillations are directly related to sensorimotor integration, and fixed pattern of stimulus presentation (i.e., fixed condition) is associated with sequencing motor programming of saccadic eye movement, we were expecting to find higher inter-hemispheric correlation over central areas for fixed condition. The present paper is relevant since SEM is an important tool used to understand the relationship between brain, behavior and cognitive aspects allowing for the comprehension of some neurological diseases (e.g., Parkinson's and Huntington's Diseases) ${ }^{10,11}$ and psychiatry disorders (e.g., bipolar disorder, depression, and schizophrenia) $)^{1,12}$. Hence, this study has analyzed, through the coherence of the beta band (qEEG), neurophysiological interactions of saccade movements in order to contribute to future researches in this field.

\section{METHODS}

Twelve healthy volunteers (three male; mean age of 26.25 years-old, $\mathrm{SD}=4.13$ ) were recruited for this study. All participants had normal or corrected to normal vision and no sensory, motor, cognitive or attention deficits, which would affect the SEM. Subjects signed a consent form, which thoroughly described the experimental procedure. The experiment was approved by the Ethics Committee of the Psychiatric Institute of Federal University of Rio de Janeiro (IPUB/UFRJ).

\section{Task procedure}

Subjects were seated on a comfortable chair in a darkened and sound-protected room in order to minimize sensory interference. At the eye level of participants, a bar composed of 30 light emitting diodes (LEDs) was positioned with 15 of them located on the left side of fixation, and 15 on the right one (Fig 1A). The bar had a length of $120 \mathrm{~cm}$. The distance between participants' eyes and the LED bar was standardized to $100 \mathrm{~cm}$. Computer software controlled the LED bar and determined the presentation of the stimulus. Participants were asked to keep their eyes fixed on the center of the bar, and to shift their eyes when they perceived one of the diodes lighting up. Participants were instructed to follow the LEDs with their eyes, in such way that their heads remained static.

The SEM paradigm consisted of two different conditions: a fixed and a random pattern (Fig 1B). In the fixed pattern, the target stimulus (target LED) always appeared at a predefined position, i.e. LED 12, of either the left or right side (alternating between left and right). This condition is characterized by the predictability of the appearance of the stimulus at a predefined spatial location in the periphery of the visual field. In contrast, the random pattern presented a 
fully randomized series of target LEDs at completely unpredictable spatial positions across the central, and both peripheral visual fields (the light could appear at any of the 30 LEDs). In both conditions, each LED remained lit for $250 \mathrm{~ms}$, with an inter-LED time of two seconds. Each participant underwent 12 consecutive blocks, six ones fixed SEM and six others random SEM, with 20 trials per block. The probability of a light to appear on the left or right sides was counterbalanced within and across blocks, like the both SEM conditions.

\section{EEG data acquisition}

The International 10/20 EEG electrode system $^{13}$ was used with a 20-channel EEG system (Braintech-3000, EMSAMedical Instruments, Brazil). The 20 electrodes were arranged on a nylon cap (ElectroCap Inc., Fairfax, VA, USA), yielding monopolar derivations using the earlobes reference. Impedance of EEG and electrooculogram (EOG) electrodes was kept between 5-10 k $\Omega$. Data recorded had a total amplitude of less than $70 \mu \mathrm{V}$. The EEG signal was amplified with a gain of 22.000, analogically filtered between 0.01 (high-pass) and $80 \mathrm{~Hz}$ (low-pass), and sampled at $200 \mathrm{~Hz}$. The software Data Acquisition (Delphi 5.0), at the Brain Mapping and Sensory Motor Integration Lab, was employed with the following digital filter: notch $(60 \mathrm{~Hz})$.

\section{Saccadic eye movement acquisition}

Four additional electrodes of $9 \mathrm{~mm}$ in diameter mounted on a bipolar form were used to measure the EOG. Electrodes were arranged horizontally from the outer canthi of both eyes to determine the horizontal EOG (hEOG) and vertically above both eyes to determine the vertical EOG (vEOG).

\section{Data processing and analysis}

We applied a visual inspection and independent component analysis (ICA) to remove possible sources of artifacts produced by the task (i.e., blink, muscles, and saccade-related artifacts). Data were collected using the biauricular reference and they were transformed (re-referenced) using the average reference, after the artifact elimination using ICA was conducted. We removed those trials that clearly showed a blink and a saccade-related artifacts 'influence' by visual inspection and the components that showed blink and saccade-related artifacts 'contamination', using ICA.

A classic estimator was applied for the power spectral density (PSD), or directly from the square modulus of the Fourier Transform (FT), which was performed by MATLAB 5.3 (Matworks, Inc.). The number of samples was $800(4 \mathrm{~s} \times 200 \mathrm{~Hz})$ with rectangular windowing. We extracted quantitative EEG parameters within a time window between $500 \mathrm{msec}$, before the stimulus presentation, and $500 \mathrm{msec}$ after the target stimulus (LEDs); the selected epoch started 500 msec before and ended 500 msec after the trigger, i.e.,

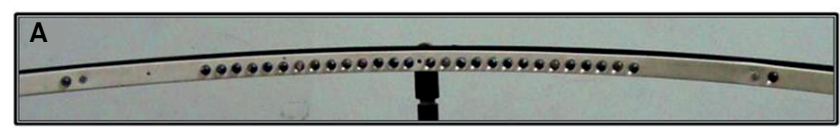

B

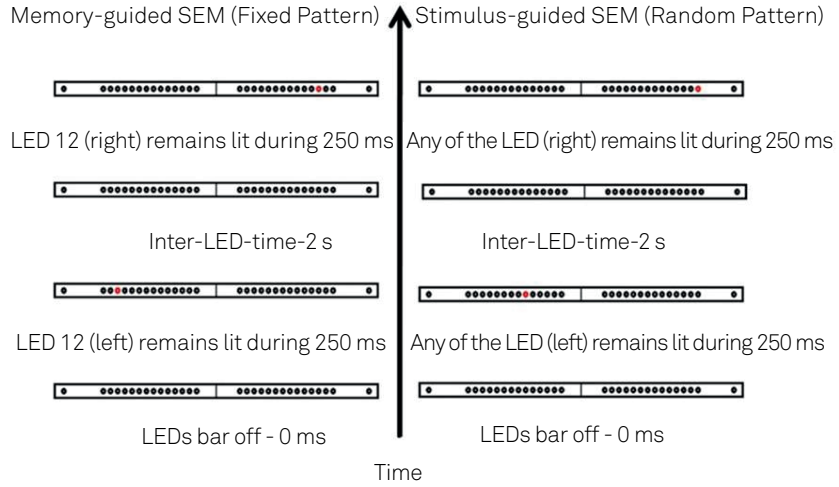

Fig 1. (A): Photograph of the light emitting diodes (LED) bar set-up. (B): Illustration of the experimental time course of the two saccadic eye movement (SEM) conditions. Left panel: fixed condition. Right panel: random condition.

moment 1 and 2, respectively. Thereafter, all raw EEG trials were visually controlled, and trials contaminated with ocular or muscle artifacts were discarded. The FT resolution was $1 / 4 \mathrm{~s}-0.25 \mathrm{~Hz}$ Fast Fourier Transform (FFT). To examine a stationary process, the run and reverse-arrangement tests were applied. Mainly, the stationary process was accepted for each four seconds (epoch's duration in this period). In this manner, based on artifact-free EEG epochs, the threshold was defined by the mean plus three standard deviations with epochs, showing a total power higher than this threshold not being included into the analysis.

\section{Statistical analysis}

Beta coherence $(12 / 30 \mathrm{~Hz})$ was the dependent variable. Statistical analysis of beta coherence were performed by a two-way ANOVA, with the condition factors (two levels: fixed versus random SEMs) and moment (two levels - pre and poststimulus). All tests were performed in pairs of electrodes (F3/ F4, FZ/F3, FZ/F4, C3/C4, CZ/C3, CZ/C4, P3/P4, P3/PZ, PZ/ $\mathrm{P} 4, \mathrm{O} 1 / \mathrm{O} 2, \mathrm{O} 1 / \mathrm{OZ}$, and $\mathrm{OZ} / \mathrm{O} 2$ ).

\section{RESULTS}

The present study examined beta coherence in the fixed and random experimental conditions over the frontal (F3/F4, FZ/F3, FZ/F4), central (C3/C4, CZ/C3, CZ/C4), parietal (P3/ $\mathrm{P} 4, \mathrm{P} 3 / \mathrm{PZ}, \mathrm{PZ}, \mathrm{P} 4)$, and occipital (O1/O2, O1/OZ, OZ/O2) cortexes. We performed a two-way ANOVA to investigate each electrode pair separately, which revealed an interaction between moment and condition factors ( $\mathrm{F}=4.153 ; \mathrm{p}=0.042$ ), and a main effect for condition $(\mathrm{F}=8.669 ; \mathrm{p}=0.003)$ and moment $(\mathrm{F}=9.798 ; \mathrm{p}=0.002)$ for the $\mathrm{C} 3 / \mathrm{C} 4$ pair of electrodes. Examining 
the interaction between the pair of electrodes C3/C4, we performed a $t$-test between conditions (e.g. random versus fixed) for each moment (e.g. pre and post) separately (Fig 2).

We have detected a significant difference between the two conditions, with greater beta coherence at fixed condition at the pre-moment $(\mathrm{p}=0.001)$. We observed no significance in the fixed condition at post-moment $(\mathrm{p}=0.734)$. For the $\mathrm{CZ} / \mathrm{C} 4$ electrodes, we have seen a main effect for moment $(F=9.266 ; p=0.002)$, as seen in Fig 3. For FZ/F4 electrodes, we have seen a main effect for condition ( $\mathrm{F}=15.371 ; \mathrm{p}=0.001)$, as in Fig 4. In the analysis of the FZ/F3 electrodes, it was verified a main effect for moment $(\mathrm{F}=7.623 ; \mathrm{p}=0.005)$, as in Fig 5 and 6. For the pairs of electrodes CZ/C3 and F3/F4, we did not find any statistically significant result. For P3/P4 (Fig 7A) and $\mathrm{O} 1 / \mathrm{O} 2$ (Fig 8) pairs of electrodes, we found a main effect for condition $(\mathrm{F}=5.747 ; \mathrm{p}=0.017$, and $\mathrm{F}=7.628$; $\mathrm{p}=0.006$, respectively) and for P3/PZ (Fig 7B) pair of electrodes we detected a main effect for moment $(\mathrm{F}=4.521 ; \mathrm{p}=0.034)$. We did not find a significant statistic for the pairs of electrodes PZ/P4, O1/ $\mathrm{OZ}$, and $\mathrm{OZ} / \mathrm{O} 2$.

\section{DISCUSSION}

The present study investigated changes in beta coherence over the frontal and motor corteces, while performing a task involving the SEM. Specifically, the following pairs of electrodes were analyzed: F3/F4, FZ/F3, FZ/F4, C3/C4, CZ/ C3, CZ/C4, P3/P4, PZ/P4, PZ/P3, O1/O2, OZ/O1, and OZ/ O2. For the C3/C4, CZ/C4, FZ/F3, FZ/F4, P3/P4, P3/PZ and O1/O2 electrodes pairs, we observed significant differences. The participants were exposed to two different experimental conditions: fixed and random. In the first one, the target stimulus was predictable (e.g. the 12 LED), only alternating the side of the bar, left or right. In the random condition, the

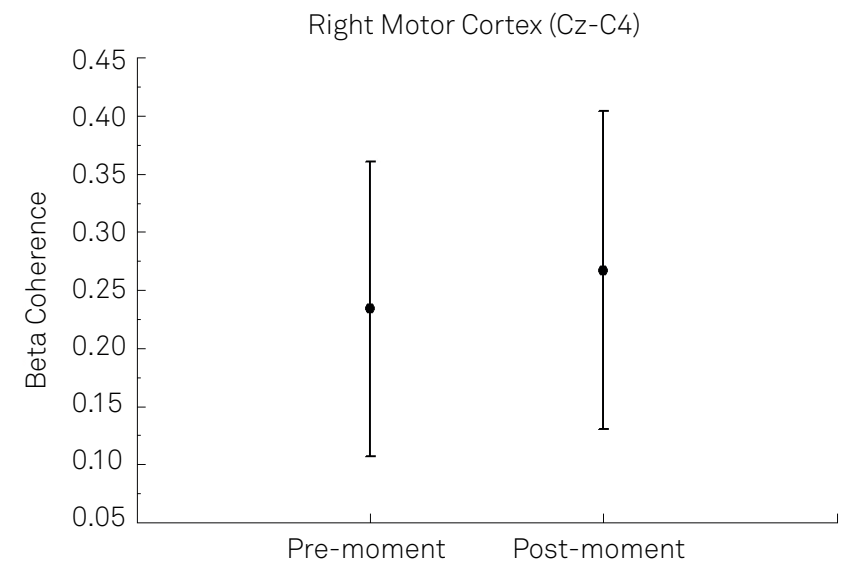

Fig 3. Mean and standard deviation of beta coherence on right motor cortex (Cz-C4) at pre and post moment. The statistical analysis revealed a main effect for moment ( $p=0.002)$.

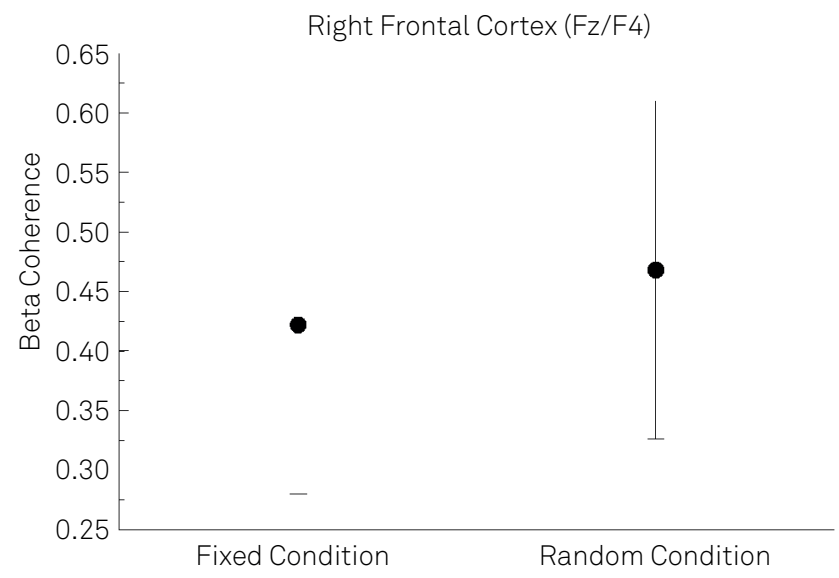

Fig 4. Mean and standard deviation of beta coherence on right frontal cortex (Fz/F4) at fixed and random condition. The statistical analysis revealed a main effect for condition $(p=0.001)$.

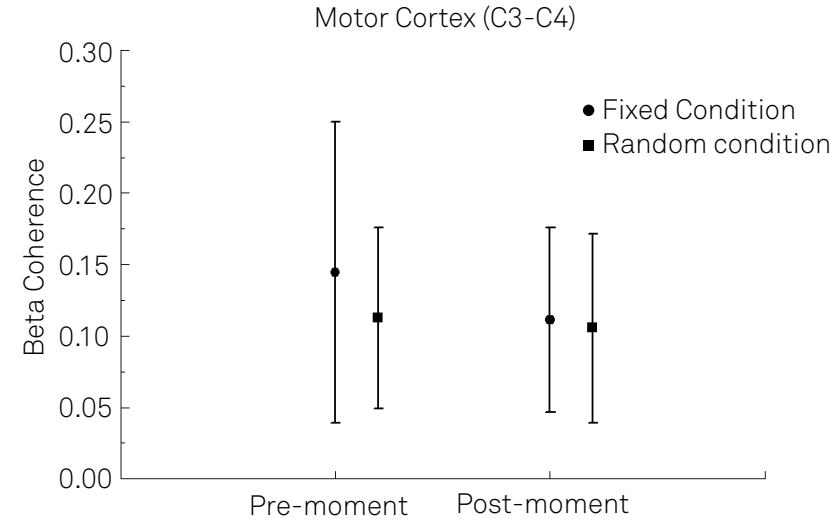

Fig 2. Mean and standard deviation of beta coherence on motor cortex (C3-C4) region at fixed and random conditions during the pre and post-moments. The statistical analysis revealed an interaction between the factors main effect of time point $(p=0.042)$.

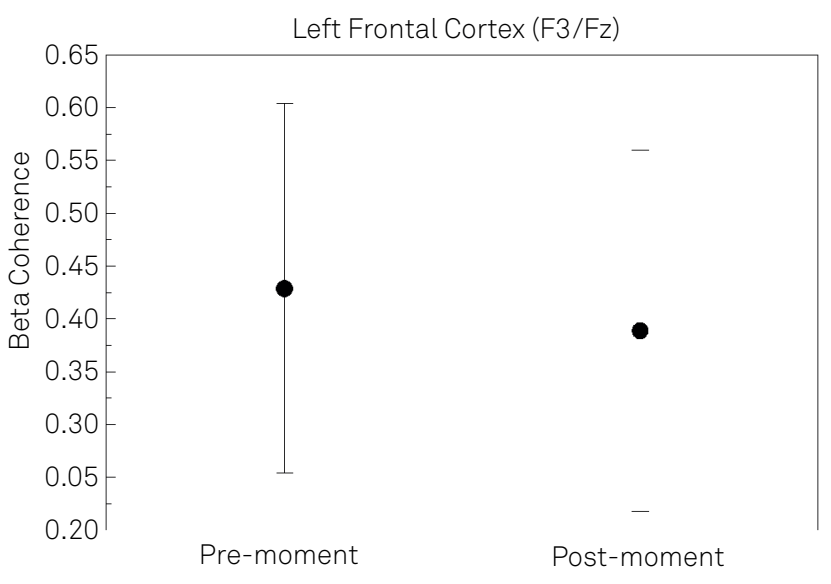

Fig 5. Mean and standard deviation of beta coherence on left frontal cortex (Fz/F3) at pre and post-moments. The statistical analysis revealed a main effect for moment $(p=0.005)$. 
A

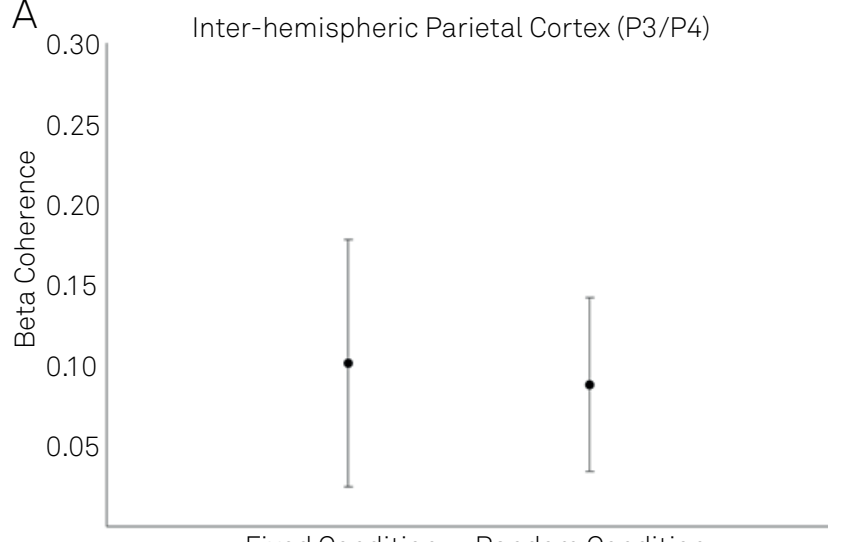

Fixed Condition Random Condition

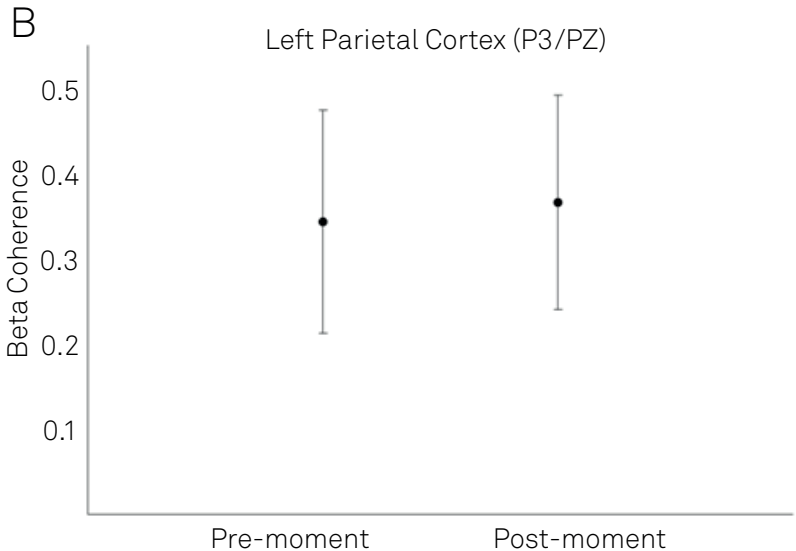

Fig 6. Mean and standard deviation of beta asymmetry on parietal cortex. (A) Inter-hemispheric parietal cortex (P3/P4) at fixed and random conditions. The statistical analysis revealed a main effect for condition ( $p=0.017$ ). (B) Left parietal cortex $(\mathrm{P} 3 / \mathrm{Pz})$ at pre and post-moments. The statistical analysis revealed a main effect for moment $(p=0.034)$.

target stimulus could be any of the 30 LEDs of the bar. Thus, its main feature is the unpredictability of the target stimulus, i.e., the participant could not predict which of the LEDs would light up, being guided directly by the stimulus. This condition requires a greater level of attention, since there is a greater engagement in the process of visual search ${ }^{14}$.

Motor cortex: planning, control, and execution of voluntary motor functions

We investigated beta coherence for $\mathrm{C} 3 / \mathrm{C} 4, \mathrm{CZ} / \mathrm{C} 3$ and $\mathrm{CZ} / \mathrm{C} 4$ pairs of electrodes. We observed an interaction between the factors condition and moment for $\mathrm{C} 3 / \mathrm{C} 4$ (Fig 6), we also observed a main moment effect for $\mathrm{CZ} / \mathrm{C} 4$. Examining the interaction, we observed a beta coherence increase for the fixed condition when compared to the random one before the stimulus presentation. We have also detected a difference between pre and post-moments in the fixed condition, not being verified the same for random condition.

The motor cortex is involved in planning, executing, and controlling voluntary movement. Specifically, the C3 and C4
Inter-hemispheric Occiptal Cortex (01/02)

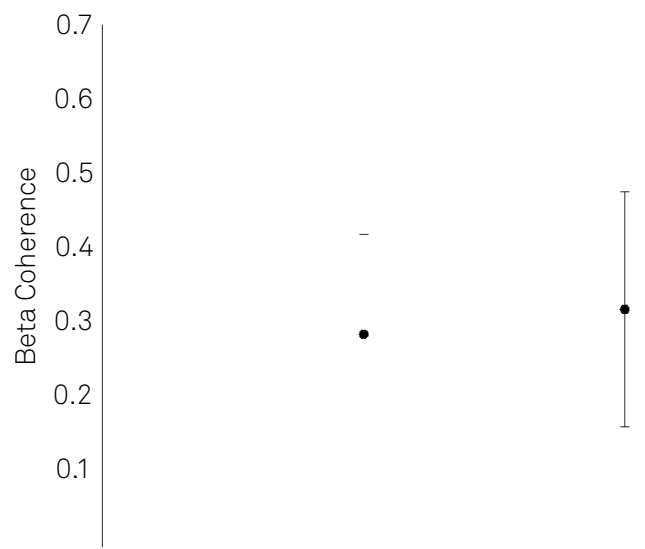

Fixed Condition Random Condition

Fig 7. Mean and standard deviation of beta asymmetry on inter-hemispheric occipital cortex (01/02), at fixed and random conditions. The statistical analysis revealed a main effect for condition ( $p=0.006$ ).

\section{C3-C4 Cross-Coherence}

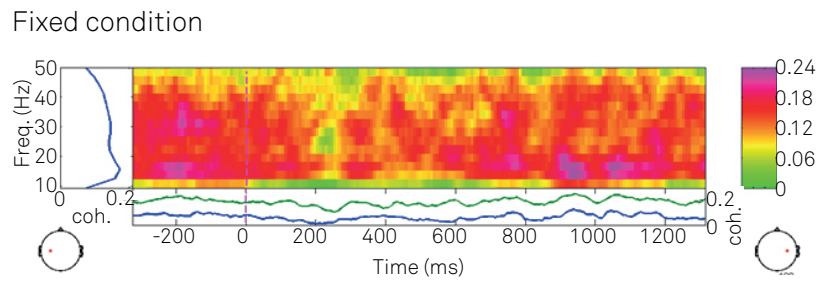

Random condition

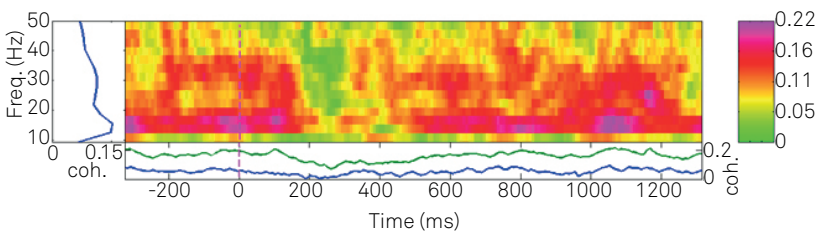

Fig 8. Cross-coherence of C3 and C4 electrodes.

electrodes are located over the Broadman's areas 6 and 4, which are also related to the frontal eye field (FEF), a region responsible for controlling visual attention and motor execution of voluntary saccades ${ }^{8}$. We observed increase beta coherence for fixed condition in the pre-stimulus moment, when compared to the random one, this result points out to higher intercommunication between these areas in beta frequency before the fixed condition. Beta coherence has been associated with movement preparation and visual perception ${ }^{15}$, representing the sensorimotor integration processes ${ }^{16}$.

The difference between conditions before the LED lights shows that the strategy of visual search and movement preparation is different between both conditions. We observed an increased communication between $\mathrm{C} 3$ and $\mathrm{C} 4$ 
electrodes during the fixed condition, suggesting that this task requires more engagement of the motor cortex during visual search (e.g., attention orientation) and movement preparation. A recent study examined the activation of brain areas relevant to saccade preparation and to the orientation of attention through the EEG. They identified a pattern of spatiotemporal and functional overlapping between attention preparation and saccade orientation.

Specifically, an increased communication between the two hemispheres shows greater engagement of those cognitive functions.

In our study, the spatiotemporal and functional overlapping pattern may explain the increased coherence found in the fixed condition, which involves attention preparation and saccade orientation, contrarily to the random condition, where the stimulus unpredictability does not allow the existence of an overlap between these two functions, once this condition does not favor a motor sequencing programming, and a consequent reinforcement of the communication between the left and right motor cortices.

Therefore, our findings are in agreement with what was seen in Van der Lubbe et al. The reduction of beta coherence for fixed condition during the post-stimulus moment can also be described as a decline of the focus of attention during the task performance ${ }^{17}$.

In the $\mathrm{CZ} / \mathrm{C} 4$ pair of electrodes, we saw a main effect for moment. We observed a beta coherence increase at the post-moment when compared to the pre-stimulus one. Specifically, the increase in beta coherence at the post-moment suggests a greater communication between the medial motor areas (CZ) and right motor (C4) after stimulus presentation, and subsequent execution of the saccadic movement. We did not find any significant results for $\mathrm{CZ} / \mathrm{C} 3$. According to these results, the right central cortex differentiates the pre and post moments of the saccadic execution, which was not observed in the left hemisphere. This finding is related to the specificity of the right hemisphere in processing spatial information. Therefore, the result in $\mathrm{CZ} / \mathrm{C} 4$ is associated with the coordination of spatial visual processing in this hemisphere $^{18}$. Based on our findings, we conclude that there is a greater involvement of both hemispheres in the visual search and movement preparation; in especial the coherence increment in beta at the post-moment, in the fixed condition, shows an automated action and the focus of attention reduction during the execution of the task. Moreover, we have observed a greater participation of the right hemisphere when compared to the left one, once the latter does not differentiate pre and post-moments.

\section{Frontal cortex: attention, short-term memory tasks, planning, and drive}

The beta coherence analysis over the frontal cortex showed a main effect for condition at FZ/F4 electrode sites and one for moment at the electrodes FZ/F3. For FZ/F4 areas, we observed a beta coherence decrease in the fixed condition when compared to the random condition. For the FZ/ F3 electrodes, we have seen a beta coherence decrease at the post-moment. These results demonstrate that the right frontal cortex has a special role in the distinction between the tasks, with a beta coherence reduction in fixed saccade condition when compared to the random condition. The results show that the left frontal cortex differentiates the pre and post-stimulus presentation moment, with greater beta coherence before the LED lights and a beta coherence decrease after the LEDs lights.

In a recent study, Verbruggen et al..$^{19}$ suggested an involvement of right frontal cortex in tasks requiring focused attention. In this experiment, the main task was to press J or $\mathrm{K}$ keys on a keyboard with the index finger or middle, as fast as possible, whenever a green or yellow color appeared on the monitor. During the task, there was a motor response reprogramming. This finding suggests that the right frontal cortex could be related to the selection of an action with a simultaneously planned engine. Although the focus of that article was the theta frequency band, our studies found similar results in beta. Beta has been mainly associated with motor activity ${ }^{20}$. During the motor act, the primary motor cortex shows a dramatic decrease in band amplitude. It is considered that there is a strong impact on beta when the motor act is interrupted ${ }^{16}$. Beta also has an important function in attention $^{21}$ and cognitive functions ${ }^{22}$. Our results demonstrate beta coherence reduction in the fixed condition, which points to greater involvement of procedural memory in this condition. The same result was previously observed by Portella et al. ${ }^{6}$, who investigated the changes in beta frontal areas as the participants had to perform a motor task involving typing with progressive learning paradigm. The subjects did a task with a sequence of five typing letters for each hand. The result of this experiment showed a decrease of beta coherence in the frontal area, which suggests that neuronal specialization is seen in experimental models involving sequential motor task.

Moreover, the same authors verified an increase in beta coherence in the beginning of the task with its decrease, while the subjects performed the task. In this context, our findings corroborate Portella et al. ${ }^{6}$. We interpreted these data as an association with procedural memory; the beta coherence decrease in the left frontal cortex is also explained by the task automation, e.g., the repetition of task led to the consolidation following the saccadic movement. We conclude that beta coherence reduction at the post-moment indicates that the right frontal cortex has a special role in the differentiation between tasks, with a decrease in beta coherence to the memory-guided saccade, which points to a greater involvement of memory procedure in this condition. This finding suggests neuronal specialization in experimental models involving sequential motor task. 


\section{Parietal and occipital cortexes: visuomotor attention}

We investigated beta coherence over parietal (P3/P4, P3/ $\mathrm{PZ}$ and PZ/P4) and occipital (O1/O2, OZ/O1 and OZ/O2) cortices. The electrodes over the parietal cortex represent Broadman's areas 7, 39 and 40, and they are directly related to sensorimotor integration and spatial orientation ${ }^{23}$. Electrodes O1, O2 and OZ represent Broadman's areas 17 and 18.

Our results demonstrate a main effect for condition ( $p=0.017)$ for the P3/P4 pair of electrodes. We also observed a main moment effect for the pair of electrodes P3/ $\mathrm{PZ}(\mathrm{p}=0.034)$. For PZ/P4, we did not find a significant difference. These results, particularly the main effect for condition for the pair of electrodes $\mathrm{P} 3 / \mathrm{P} 4$, demonstrate that inter-hemispheric coupling in parietal areas differentiates the two experimental conditions. Specifically, we verified an increased coherence in the beta band for the fixed condition, when compared to the stimulus-driven condition. As already pointed, the parietal lobe participates in the integration of visuospatial information, being responsible to integrate spatial perception and motor function. Thus, it organizes motor planning and spatial orientation ${ }^{23}$. The fixed condition involves the same sequencing, since the direction and localization of the target (i.e., LED) remain fixed. Therefore, our results show that this form of sequencing demands a greater coupling in the beta band between left and right parietal cortices for the fixed condition. On the other hand, for the P3/PZ electrode pairs, we found increased beta coherence after stimulus presentation. This result indicates that the left parietal cortex is modulated by the execution of SEM. In other words, after stimulus presentation (and during performance), there is greater participation of this region, corroborating previous data pointing for the involvement of this area in sensorimotor integration processes ${ }^{16}$.

The analysis of $\mathrm{O} 1 / \mathrm{O} 2$ electrode pairs, located over occipital cortex, showed a main effect for condition, with increased beta coherence for the random condition. The occipital lobe is subdivided into primary visual cortex, responsible for the detection of visual stimulus, and associative visual cortex, which is intimately involved in the processing and comprehension of visual information ${ }^{17}$. These finding suggest that the identification of the stimulus during the task in the stimulus-driven condition demands a greater participation of the associative visual cortex, since this area is responsible for the motor organization of information in the construction of visual images, i.e., it organizes the representation of the stimulus received in the primary visual cortex ${ }^{24-26}$.

\section{CONCLUSIONS}

The present paper investigated the changes in beta coherence on the frontal, motor, parietal and occipital cortices during the performance of two distinct SEM paradigms, involving different patterns of stimulus presentation: a fixed and a random condition. The results showed that there was an inter-hemispheric connection during the visual search and the preparation of the movement. We also found decreased attention levels during the task execution. Therefore, the conclusion was that the areas investigated actively participate in the control and execution of SEM, and that there is neuronal specialization in experimental models involving sequencing motor tasks.

\section{References}

1. Harris MSH, ReillyJL, Thase ME, Keshavan MS, Sweeney JA. Response suppression deficits in treatment-naive first-episode patients with schizophrenia, psychotic bipolar disorder and psychotic major depression Psychiatry Res 2009;170:150-156.

2. Squire LR, Berg D, Bloom FE, et al. Fundamental neuroscience (third edition). San Diego: Academic Press; 2008.

3. Shipp S. The brain circuitry off attention. Trends Cogn Sci 2004;5:223-230.

4. Serrien DJ, Strens LH, Cassidy MJ, Thompson AJ, Brown P. Functional significance of the ipsilateral hemisphere during movement of the affected hand after stroke. Exp Neurol 2004;190:425-432.

5. Silva JG, Knackfuss IG, Portella CE, et al. Coerência espectral do eletroencefalograma em pacientes submetidos à transposição tendinosa - Estudo pré e pós-operatório. Arq Neuropsiquiatr 2006;64:473-477.

6. Portella CE, SilvaJG, Bastos VH, et al.Aprendizagem de procedimentos e efeitos ansiolíticos - Medidas eletrencefalográficas, motora e atencional. Arq Neuropsiquiatr 2006;64:478-484.

7. Posner MI, Petersen SE. The attention system of the Human Brain. Annu Rev Neurosci 1990;13:25-42.

8. Mcdowell JE, Dyckman KA, Austin BP, Clementz BA. Neurophysiology and neuroanatomy of reflexive and volitional saccades: evidence from studies of humans. Brain Cogn 2008;68:255-270.

9. Pfurtscheller G, Woertz MG, Supp FH, Lopes da Silva FH. Early onset of post-movement beta electroencephalogram synchronization in the supplementary motor area during self-paced finger movement in man. Neurosci Lett 2003;339:111-114.

10. Van Stockum S, Macaskill MR, Myall D, Anderson TJ. A perceptual discrimination task abnormally facilitates reflexive saccades in Parkinson's disease. Eur J Neurosci 2011;33:2091-2100.

11. Rupp J, Dzemidzic M, Blekher T, et al. Abnormal error-related antisaccade activation in premanifest and early manifest Huntington disease. Neuropsychology 2011;25:306-318.

12. Gooding DC, Tallent KA. The association between antisaccade task and working memory task performance inschizophrenia and bipolar disorder. J Mental Dis 2001;189:8-16.

13. Jasper $H$. The ten-twenty electrode system of the international federation. EEG Clin Neurophysiol 1958;10:371-375.

14. Baddeley AD. The episodic buffer: a new component of working memory? Trends Cogn Sci 2000;4:417-423. 
15. Smith M, McEvoy L, Gevins A. Neurophysiological indices of strategy development and skill acquisition. Cogn Brain Res 1999;7:389-404.

16. Neuper C, Pfurtscheller G. Evidence for distinct beta resonance frequencies in human EEG related to specific sensorimotor cortical areas. Clin Neurophysiol 2001;112:2084-2097.

17. Van der Lubbe RH, Neggers SF, Verleger R, Kenemans JL. Spatiotemporal overlap between brain activation related to saccade preparation and attentional orienting. Brain Res 2006;1072:133-152.

18. Garoff, RJ, Slotnick, SD, Schacter DL. The neural origins of specific and general memory: the role of the fusiform cortex. Neuropsychologia 2005;43:847-859.

19. Verbruggen F, Aron AR, Stevens MA, Chambers CD. Theta burst stimulation dissociates attention and action updating in human inferior frontal cortex. PNAS 2010;107:13966-13971.

20. Zhang Y, Chen Y, Bressler SL, Ding M. Response preparation an inhibition:the role of the cortical sensoriomotor beta rhythm. Neuroscience 2008;156:238-246.

21. Bekisz M, Wróbel A. Attention-dependent coupling between beta activities recorded in the cat's thalamic and cortical representations of the central visual field. Eur J Neurosci 2003;17:421-426.

22. Razumnikova OM. Gender differences in hemispheric organization during divergent thinking: an EEG investigation in human subjects. Neurosci Lett 2004;362:193-195.

23. Belebaum C, Hoffmann KP, Daum I. Post-saccadic updating of visual space in the posterior parietal cortex in humans. Behav Brain Res 2005;163:194-203.

24. Mattei TA, Mattei JA. The spatial cognition and its disturbances: the role of the posterior parietal cortex. Rev Neuroci 2005;13:93-99.

25. Merriam EP, Genovese CR, Colby CL. Remapping in human visual cortex.J Neurophysiol 2007;97:1738-1755.

26. Gonçalves LA, Melo SR. The biological bases of attention. Arq Cienc Saúde Unipar (Umuarama) 2009;13:67-71. 
ARQ NEUROPSIQUIATR 2012;70(7).

TABLE OF CONTENTS, onde se lê:

506 Cognitive mechanisms and motor control during a saccadic eye movement task: evidence from quantitative electroencephalography Mecanismos cognitivos e controle motor durante uma tarefa de movimento sacádico dos olhos: evidências de eletroencefalografi a quantitativa Diniz C, Velasques B, Bittencourt J, Peressuti C, Machado S, Teixeira S, Santos JL, Salles JI, Basile LF, Anghinah R, Cheniaux E, Nardi AE, Cagy M, Piedade R, Arias-Carrión O, Ribeiro P
Leia-se:

506 Cognitive mechanisms and motor control during a saccadic eye movement task: evidence from quantitative electroencephalography Mecanismos cognitivos e controle motor durante uma tarefa de movimento sacádico dos olhos: evidências de eletroencefalografi a quantitativa Diniz C, Velasques B, Bittencourt J, Peressutti C, Machado S, Teixeira S, Santos JL, Salles JI, Basile LF, Anghinah R, Cheniaux E, Nardi AE, Cagy M, Piedade R, Arias-Carrión O, Ribeiro P 